\title{
Long-term trends in precipitation and temperature in the Norwegian Arctic: can they be explained by changes in atmospheric circulation patterns?
}

\author{
I. Hanssen-Bauer*, E. J . Førland \\ Norwegian M eteorological Institute, PO Box 43 Blindern, N-0313 0 slo, N orway
}

\begin{abstract}
Observations from the Norwegian Arctic show positive trends in annual mean temperatures from 1912 to the 1930s and from the 1960s to 1996. Between these periods there was a negative trend, and there is no statistically significant trend in the record as a whole. The present temperature is approximately the same as in the 1920s, and lower than during the 1930s and 1950s. Spring is the only season which shows a statistically significant warming from 1912 to 1996 . Annual precipitation, on the other hand, has increased in the Norwegian Arctic. At Spitsbergen the measurements show a statistically significant increase in annual and in spring, summer and autumn precipitation. M onthly values of mean sea level pressure of 4 grid points were used to develop models for monthly mean temperature and monthly precipitation at Spitsbergen. During the period 1912 to 1993 the temperature model accounts for 30 to $45 \%$ of the variance in the seasonal mean temperatures. The correlation between observed and modelled values is at a minimum in the summer and at a maximum in the autumn. The precipitation model accounts for 15 to $35 \%$ of the variance in seasonal precipitation sums. The correlation between observed and modelled values is lowest in winter, when the problems with drifting and blowing snow are greatest. Even though the observed and modelled seasonal values in most cases are better correlated for temperature than for precipitation, the precipitation model accounts for more of the decadal scale variability and long-term trends. The precipitation model reproduces the observed positive precipitation trends on both a seasonal and annual basis. Concerning decadal scale variability, most of the main observed features are also modelled satisfactorily. It is concluded that the major observed features concerning decadal scale variability and trends in precipitation at Spitsbergen are connected to variability in the atmospheric circulation pattern. The temperature model reproduces reasonably well the observed positive trend during the last 3 decades of the series. The very low temperature before 1920 and the high values in the 1930s and the 1950s, on the other hand, are not modelled satisfactorily. Thus, while the temperature increase of the later decades may mainly be explained as a result of changes in advection, the temperature increases in the Norwegian Arctic from the beginning of the measurements to the 1930 s cannot be explained in this way.
\end{abstract}

KEY WORDS: Climate variation · Arctic $\cdot$ Atmospheric circulation $\cdot$ Temperature $\cdot$ Precipitation

\section{INTRODUCTION}

General Circulation Model (GCM) simulations of climate under higher atmospheric $\mathrm{CO}_{2}$ concentrations indicate a maximum annual mean warming in high northern latitudes (Kattenberg et al. 1996). This is true both for equilibrium and for transient experiments, though the latter show a smaller warming in the northern North Atlantic. The warming is largest in late au-

*E-mail: i.hanssen-bauer@dnmi.no tumn and winter, largely due to sea ice forming later in the warmer climate. The simulated maximum warming of the Arctic could suggest that the 'greenhouse signal' will first be detected in this area. This is not necessarily true, as the natural interannual temperature variation is also large in this region, and thus reduces the signal-tonoise ratio. Furthermore, Kattenberg et al. (1996) state that the details of the modelled changes in the Arctic climate are sensitive to the parameterization of sea ice, including the specification of sea ice albedo. Still, monitoring long-term climatic variations in the Arctic is of 
great importance. Analysing variability in climatic elements will increase our knowledge of the Arctic climate, which is poorly understood in many respects.

In the present paper, high quality series of monthly mean temperature and precipitation in the Norwegian Arctic from 1912 to 1996 are analysed. An effort is made to assess the degree to which the rather large decadal scale and long-term variations in these series reflect changes in atmospheric circulation alone, as expressed by the mean sea level pressure field.

\section{DATA AND DEFINITIONS}

The present analyses are based upon monthly mean temperature and monthly precipitation series from Svalbard Airport, and monthly mean sea level air pressure at 4 grid points (Fig. 1). Temperature ( $T$ ) and precipitation (P) time series from the Norwegian Arctic stations were recently improved by comprehensive quality control and homogeneity testing, and prolonged by gap-filling and combining different series (N ordli et al. 1996). The series valid for Svalbard Airport start in 1912. Both the temperature and the precipitation series were compiled using measurements at several locations. All gaps were filled with the exception of a gap in the precipitation series from 1941 to 1945.

The gridded set of monthly averaged sea level air pressure (SLP) for the period 1873 to 1993 developed at the University of East Anglia was used. The resolution

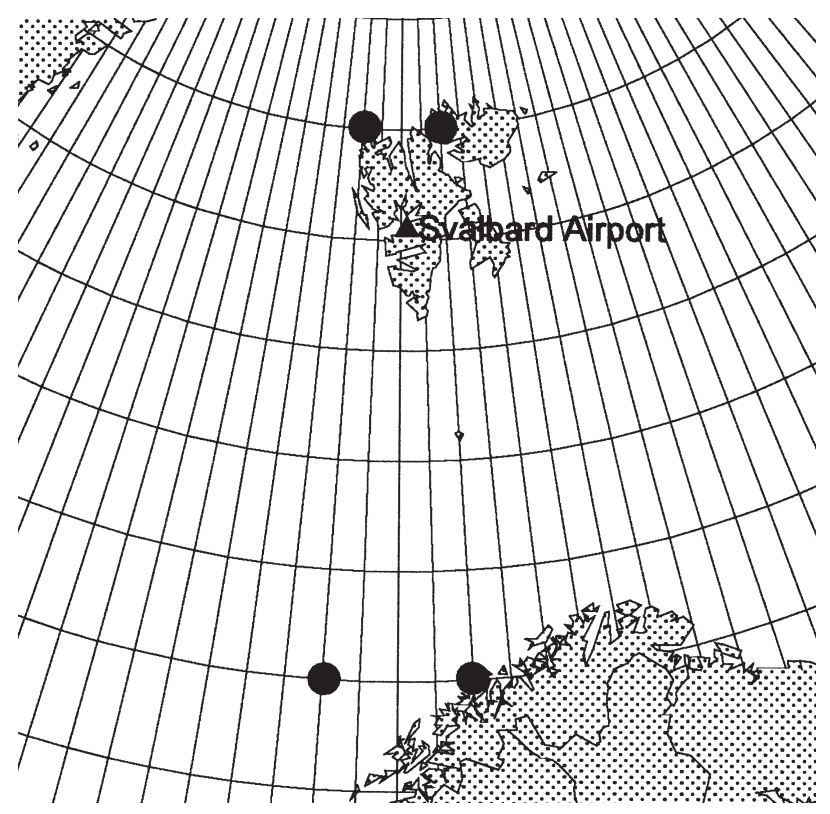

Fig. 1. The Norwegian Arctic including Svalbard Airport ( $\mathbf{\Delta})$, and the 4 grid points $(\bullet)$ at which mean sea level pressure is used of this data set north of $70^{\circ} \mathrm{N}$ is $10^{\circ}$ prior to 1940 , and $5^{\circ}$ for later years. For the present study, we used data from the grid points $70^{\circ} \mathrm{N}, 10^{\circ} \mathrm{E} ; 80^{\circ} \mathrm{N}, 10^{\circ} \mathrm{E} ; 70^{\circ} \mathrm{N}$, $20^{\circ} \mathrm{E}$; and $80^{\circ} \mathrm{N}, 20^{\circ} \mathrm{E}$ (Fig. 1). From these gridpoints, the mean $\operatorname{SLP}(p)$, zonal pressure difference $\left(\Delta p_{z}\right)$, and meridional pressure difference $\left(\Delta p_{M}\right)$ representative for Svalbard Airport were defined. The following definitions were found to give the best modelling results:

$$
\begin{aligned}
\Delta p_{z} \equiv \frac{1}{2}\left[\left(p_{70,20}+p_{80,20}\right)-\left(p_{70,10}+p_{80,10}\right)\right] & \\
\Delta p_{M} & \equiv p_{80,20}-p_{70,20} \\
p & \equiv p_{80,20}
\end{aligned}
$$

The difference between meridional and zonal resolution might affect the model as finer scales are resolved by the west-east gridding than by the southnorth gridding. However, for the period 1953 to 1993, basically identical results were found by using data from $75^{\circ} \mathrm{N}$ instead of $70^{\circ} \mathrm{N}$. It was thus concluded that the difference in scale is of limited importance.

\section{METHODS}

Multiple linear regression was used to establish relations between the monthly averaged geostrophic wind components and absolute pressure (predictors) and local monthly mean temperature and monthly precipitation sum (predictands). The regression models for any month ( $n$ ) may then be expressed as

$$
\begin{aligned}
& x_{n, i}-\overline{x_{n, i}}=\left(\Delta p_{Z, n}-\overline{\Delta p_{Z, n}}\right) \cdot a_{n, i}-\left(\Delta p_{M, n}-\overline{\Delta p_{M, n}}\right) \cdot b_{n, i} \\
&+\left(p_{n}-\overline{p_{n}}\right) \cdot c_{n, i} \\
& n \in\{1,12\}, i=T \text { or } P
\end{aligned}
$$

Here, $x_{n, T}$ is monthly mean temperature, $x_{n, P}$ is monthly precipitation and $a_{n}, b_{n}$ and $c_{n}$ are regression coefficients. Overbar symbolises averaging over some 'model training period'. The regression equations express the relations between deviations from long-term averages.

Instead of using the regression coefficients directly, they were modified somewhat in an attempt to increase the interpretability and consistency of the final models. In order to distinguish between original and adjusted coefficients, the latter are denoted by capital letters. Consequently, estimated mean temperature $X_{n, T}$ and precipitation sum $X_{n, P}$ are given as

$$
\begin{aligned}
& x_{n, i}= \overline{x_{n, i}}+\left(\Delta p_{z, n}-\overline{\Delta p_{Z, n}}\right) \cdot A_{n, i}-\left(\Delta p_{M, n}-\overline{\Delta p_{M, n}}\right) \cdot B_{n, i} \\
&+\left(p_{n}-\overline{p_{n}}\right) \cdot C_{n, i} \\
& n \in\{1,12\}, i=T \text { or } P
\end{aligned}
$$

The adjustments of the coefficients were partly based upon seasonal smoothing and partly motivated by physical considerations. In the temperature equation, 
the 2 pressure difference terms (geostrophic wind terms) may be interpreted as 'monthly mean advection terms'. The first one represents the meridional advection. The coefficient $A_{n, T}$ should thus be proportional to the 'typical monthly meridional temperature gradient' for month $\mathrm{n}$. In the Norwegian Arctic, this gradient is positive all year around, and largest during winter (e.g. Vowinckel \& Orvig 1970). Thus $A_{n, T}$ is expected to be positive for all months, with a maximum during winter. The coefficient $B_{n, T}$ should be proportional to the 'typical monthly zonal temperature gradient' for month $\mathrm{n}$. As Svalbard Airport is situated on the west coast of Spitsbergen, $B_{n, T}$ is expected to be positive when sea is warmer than land. In the Arctic, this is the case for all seasons except summer. The physical interpretation of the pressure term in the temperature equation is not connected to advection, but rather to the energy budget of the air. High pressure is correlated to subsidence, and thus to low cloudiness, while low pressure is associated with convergence, and thus a more cloudy sky. During winter and most of the autumn and spring, the Arctic clear-sky radiation budget is negative, thus contributing to surface cooling (Vowinckel \& Orvig 1970). As a cloudy sky would decrease cooling, $C_{n, T}$ is thus expected to be negative during autumn, winter and spring. During summer, on the other hand, the clearsky radiation budget is positive at most places, and $C_{n, T}$ is thus expected to be positive. Tables of net radiation in $\mathrm{Ny}$-Ålesund, Svalbard (Hisdal et al. 1992), indicate that the transition between negative and positive diurnal net radiation usually occurs in A pril and September.

The physical interpretation of the precipitation equation is somewhat different. The 2 geostrophic wind terms express that the station is mainly exposed for precipitation from one wind sector, and that it increases when the average pressure gradient in this direction increases. This is a fairly good description of the conditions at stations where orographic effects are strong. Tveito (1996) found correlation coefficients ranging from 0.68 (August) to 0.93 ( $\mathrm{March}$ ) between monthly mean onshore geostrophic wind component and monthly precipitation at a station in western Norway. Hurrell (1995) found a correlation of 0.77 between the North A tlantic Oscillation (NAO) index and the December through March precipitation in Bergen in western Norway. It is expected that the precipitation on the west coast of Spitsbergen should be orographically enhanced for westerly and southwesterly winds, while easterly and northeasterly winds leave the west coast in the rain shadow. Thus, $A_{n, P}$ and $B_{n, p}$ are expected to be positive all year around. Their absolute values may vary throughout the year, but their ratio should be approximately constant. The last term of the precipitation equation is added to include information connected to the correlation between low pressure sys- tems and precipitation. Because of the convergence effects of low pressure systems, the coefficient $C_{n, P}$ is expected to be negative for all months.

\section{MODEL DEVELOPMENT AND TESTING}

Regression analyses were performed according to Eq. (4) on monthly mean temperature and precipitation from Svalbard Airport, using even years from 1912 to 1992 as the model training period. The regression coefficients, as well as their standard errors, are given in Figs. 2 (temperature) \& 3 (precipitation). The choice of even years as the training period rather than the first or last half of the series is made in order to avoid the comparison between training and validation periods being affected by improved data quality in the more recent part of the series. A disadvantage of fitting the model to the average climate conditions of the whole period is that the validation of the model will not reveal whether the statistical relations have undergone long-term changes. However, Figs. $2 \& 3$ show that using the period 1953 to 1993 as the training period rather than even years for the whole period would give rather similar regression coefficients.

Stepwise regression was applied in order to investigate the relative importance of the predictors. For temperature, $\Delta \mathrm{p}_{\mathrm{z}}$ entered the model as the first variable for all months except $M$ ay and July, indicating that the meridional advection is the most important term concerning temperature. The values of $a_{n, T}$ are all positive (Fig. 2), at maximum during winter, and they differ significantly from zero at the $10 \%$ confidence level. For most months, $\Delta \mathrm{p}_{\mathrm{M}}$ was included in the model as the second predictor. Its regression coefficient $b_{n, T}$ has statistically significant positive values during 5 winter or spring months, while it has a statistically significant negative value in J uly. In autumn the term does not differ significantly from zero. Even if $p$ came out as the least important predictor, the regression coefficient $c_{n, T}$ differs significantly from zero in some months. In summer, it tends to be positive, while it tends to be negative in autumn, winter and spring. Further details, including complete results from the stepwise regression analyses, are reported by Hanssen-Bauer \& Førland (1998).

The arguments for not using the regression coefficients unadjusted in the final models are that $a$ few of these coefficients (e.g. $b_{T}$ in A pril and $c_{T}$ in J une) are not in accordance with the physical considerations in Section 3, and that the standard errors of the coefficients are considerable. The final choices of coefficients $A_{n, T}, B_{n, T}$ and $C_{n, T}$ (Fig. 2) were made using the following guidelines: (1) Regression coefficients from the months with highest correlation should primarily 

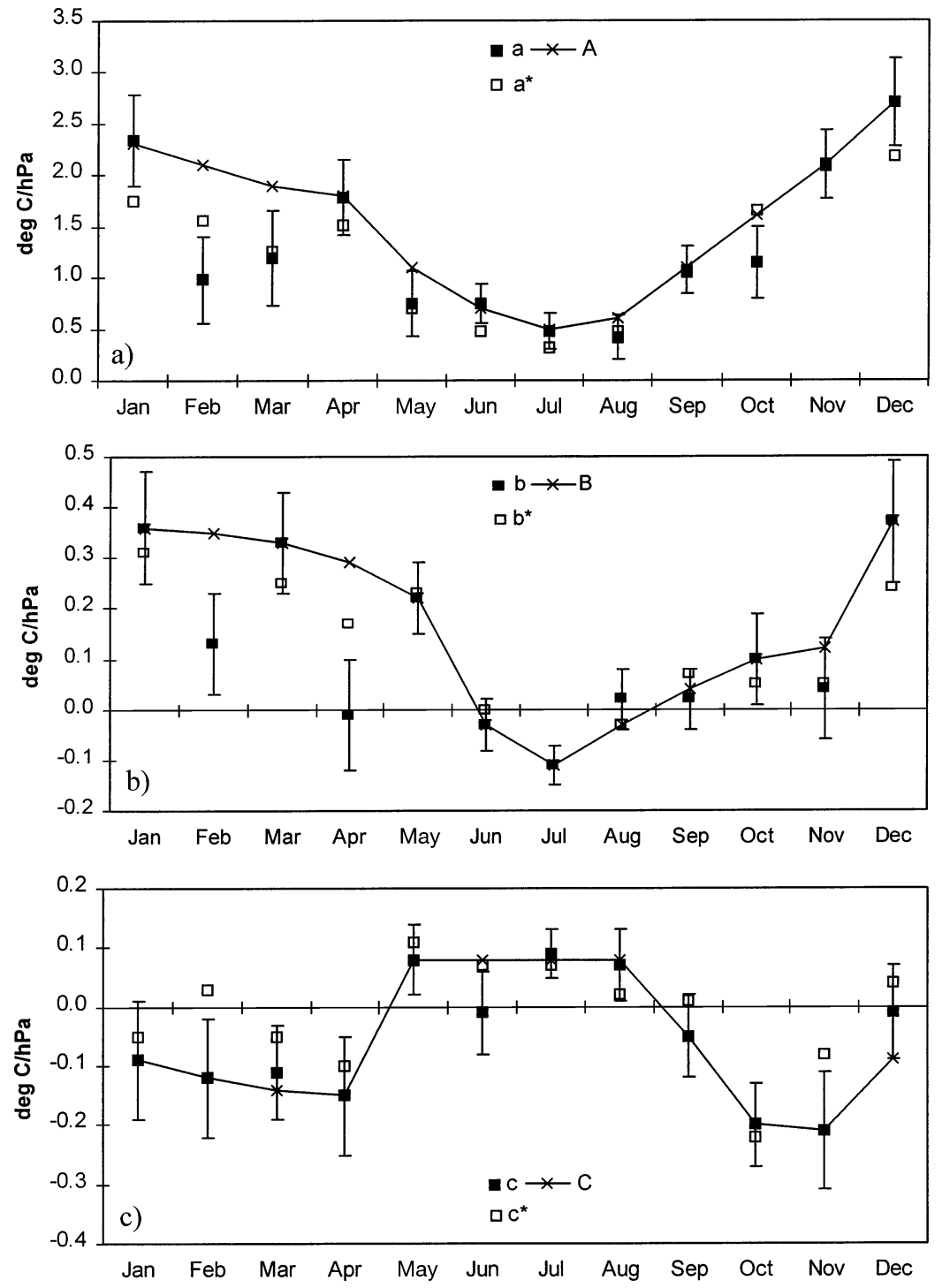

Fig. 2. Regression coefficients $a_{T}, b_{T}$ and $c_{T}$ from temperature analyses ( $(\mathbf{a})$ with standard errors (vertical lines), and final model coefficients $A_{T}, B_{T}$ and $C_{T}$ (curve) at Svalbard Airport for all months. (ם) Regression coefficients when using 1953 to 1993 as the training period $a^{*}, b^{*}$ and $c^{*}$. (a) $a_{T}, A_{T}$ and $a^{*},(b) b_{T}, B_{T}$ and $b^{*}$, (c) $\mathrm{C}_{\mathrm{T}}, \mathrm{C}_{\mathrm{T}}$ and $\mathrm{C}^{*}$

not be adjusted. (2) All final coefficients should be physically reasonable. (3) The coefficients should exhibit a consistent annual cycle: around mid-summer and winter, the coefficients are expected to show rather smooth variation from month to month, while more abrupt changes can be expected during autumn and spring. Although there is some subjectivity in this way of setting the coefficients $A_{n, T}, B_{n, T}$ and $C_{n, T}$, the final results are not very sensitive to the exact choices. Even using the regression coefficients unadjusted in the final model would not change any of the main conclusions of this paper.
Stepwise regression analysis of precipitation revealed that $\Delta \mathrm{p}_{\mathrm{M}}$ was the number one predictor for all months, and that the zonal advection thus is the most important term in the regression equation. The values of $b_{n, p}$ are all positive (Fig. 3), and 10 of the 12 values differ significantly from zero at the $10 \%$ confidence level. For most months, the predictor $\Delta p_{z}$ was included in the model at the second step in the stepwise regression. Its regression coefficient $a_{n, T}$ has positive values in 11 months, though only 2 differ significantly from zero. The predictor $p$ was included at step 3 in most months, and the regression coefficient $c_{n, P}$ never differs significantly from zero. Nevertheless, there is a clear tendency for negative values in summer and early fall, while small positive values are found during winter.

For precipitation, the final choices of coefficients $A_{n, P}, B_{n, P}$ and $C_{n, P}$ (Fig. 3) were made using the same guidelines as for temperature. The regression analyses formed a basis but, in accordance with the physical considerations at the end of Section $3, A_{n, p}$ and $B_{n, P}$ were chosen so that the ratio between them is constant throughout the year, and $C_{n, p}$ was not allowed to have positive values.

The models were tested by comparing results from the model training period (even years) to results from the validation period (odd years). Table 1 shows the correlation coefficient between observed and modelled temperature series for the respective periods, for the temperature model as well as the precipitation model. It is seen that the models give similar results for the training period and the validation period. For some months, the correlation between observed and modelled values is higher during the training period, while for other months it is higher during the validation period. This indicates that the connection between predictors and predictands found during the training period can be applied to independent data. The final models (Eq. 5) were thus applied to the entire data set in order to investigate the degree to which observed trends and variability in seasonal and annual values can be explained by variations in the mean sea level pressure field. 


\section{APPLICATION OF THE MODELS}

The final models were applied to the whole period 1912 to 1993, and hindcasts were made of seasonal and annual mean temperature and precipitation. Tables $2 \& 3$ show, for temperature and precipitation respectively, observed and modelled mean values, standard deviations and extreme values, as well as correlation coefficients on an annual and seasonal basis.

The temperature model accounts for 29 to $44 \%$ of the variance in seasonal mean temperatures, and $37 \%$ of the variance in the annual mean temperatures (Table 2). The model works best in the autumn and worst in summer. Some of the variance which is not accounted for is probably connected to the interannual variability in the sea ice and SST conditions. The sea ice distribution, which varies substantially from one year to another in this area (Vinje 1982), will obviously affect the temperature distribution, as the presence of sea ice radically affects sensible and latent heat fluxes at the surface, as well as the surface albedo.

The precipitation model accounts for only $16 \%$ of the interannual variance in winter precipitation (Table 3). This is probably partly caused by errors in the measurements. Some suspiciously high precipitation values were noted during winter and spring in the early 1920s, and also in the winter seasons around 1960. A closer inspection of the series reveals that these high observed values are caused by drifting or blowing snow. For 1921 to 1923 the composite Svalbard Airport series is based on data from a station which was very exposed to drifting/ blowing snow. The same is probably true for the period 1957 to 1964 (Nordli et al. 1996). As a rule, the effects of blowing/drifting snow are corrected for by quality control routines. However these routines have varied throughout the years, and the abovementioned high values of winter and spring precipitation are evidently due to non-corrected events. The values were not adjusted for the present analysis, as such corrections should only be made after careful examination of the whole series. Thus it seems highly probable that noncorrected contributions of blowing/drifting snow are
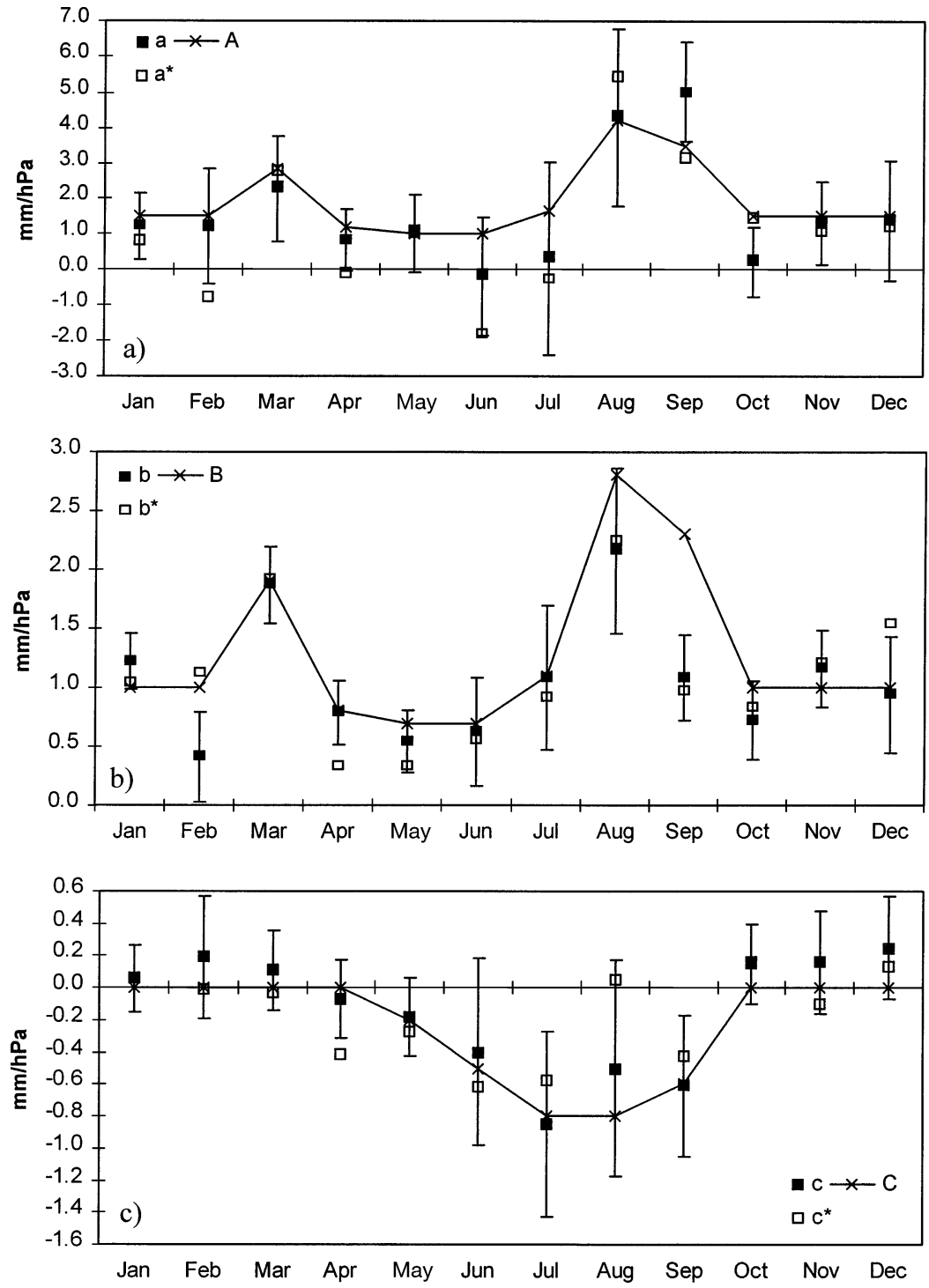

Fig. 3. Regression coefficients $a_{p}, b_{p}$ and $c_{p}$ from precipitation analyses ( $\square$ ) with standard errors (vertical lines), and final model coefficients $A_{p}, B_{p}$ and $C_{p}$ (curve) at Svalbard Airport for all months. (ם) Regression coefficients when using 1953 to 1993 as training period $a^{*}, b^{*}$ and $c^{*}$. (a) $a_{p}, A_{p}$ and $a^{*}$, (b) $b_{p}, B_{p}$ and $b^{*}$, (c) $c_{p}$, $C_{P}$ and $c^{*}$

the main reasons why the correlation between observed and modelled precipitation is at minimum during winter.

A bout $30 \%$ of the variance in annual precipitation is accounted for by the model. The main reason why the correlation coefficients between observed and modelled values in most cases are somewhat lower for precipitation than for temperature is probably that precipitation results from highly non-linear processes. The distributions of precipitation in time and space are thus generally less regular than the corresponding temperature distributions. 
Table 1. Correlation between observed and modelled variables. R: correlation coefficient between observed and modelled temperature $(T)$ or precipitation $(P)$ during the model training period (even) or validation period (odd)

\begin{tabular}{|lcccc|}
\hline & $\mathrm{R}_{\mathrm{T}, \text { even }}$ & $\mathrm{R}_{\mathrm{T}, \text { odd }}$ & $\mathrm{R}_{\mathrm{P}, \text { even }}$ & $\mathrm{R}_{\mathrm{P}, \text { odd }}$ \\
\hline J anuary & 0.73 & 0.73 & 0.67 & 0.64 \\
February & 0.52 & 0.51 & 0.30 & 0.69 \\
M arch & 0.68 & 0.44 & 0.75 & 0.66 \\
A pril & 0.48 & 0.63 & 0.58 & 0.47 \\
May & 0.55 & 0.66 & 0.47 & 0.36 \\
J une & 0.48 & 0.32 & 0.50 & 0.52 \\
July & 0.66 & 0.57 & 0.46 & 0.28 \\
August & 0.41 & 0.45 & 0.78 & 0.53 \\
September & 0.64 & 0.58 & 0.54 & 0.58 \\
October & 0.67 & 0.66 & 0.34 & 0.61 \\
November & 0.72 & 0.80 & 0.57 & 0.82 \\
December & 0.79 & 0.71 & 0.35 & 0.71 \\
& & & & \\
\hline
\end{tabular}

\section{MODELLING TRENDS IN TEMPERATURE AND PRECIPITATION AT SVALBARD}

Our objective is to investigate the degree to which long-term variability of temperature and precipitation results from variability in the circulation conditions. Even if the temperature and precipitation models account for only 37 and $30 \%$ of the interannual variance, they may be able to reproduce the decadal scale variability and long-term trends reasonably well. On these time scales, the random nature of precipitation should be smoothed out, and the precipitation model is thus not necessarily of lower skill than the temperature model.

Time series of temperature and precipitation from Svalbard were analysed by Førland et al. (1997). The Mann-Kendall test (Sneyers 1990) was applied to test the significance of trends in annual as well as seasonal records. It was concluded that the long-term variation of temperature has been similar at all Norwegian Arctic stations. The Svalbard Airport series (Fig. 4) shows no statistically significant trend in annual mean temperature during the entire period 1912 to 1996, though there are 3 periods with temperature trends significant at the $1 \%$ level: there was a positive trend from 1912 to 1930, a negative trend from the 1930s to the 1960s, and a positive trend from the 1960s to the end of the series. The present temperature is approximately the same as in the 1920s, and lower than during the 1930s and the 1950s. Spring is the only season which shows a positive temperature trend during the period as a whole.

The annual precipitation has increased in the Norwegian Arctic from the beginning of the record to the present. The precipitation series from Svalbard Airport (Fig. 5) shows positive trends, significant at the $1 \%$ level, on an annual basis and for all seasons except winter. The increase in spring precipitation occurred

Table 2. Temperature at Svalbard Airport. For the series of observed and modelled annual and seasonal temperature means from 1912 to 1993, the following values are given: mean, standard deviation, absolute minimum and absolute maximum. Corr.: correlation coefficient between observed and modelled temperature series

\begin{tabular}{|c|c|c|c|c|c|c|c|c|c|}
\hline \multirow[t]{2}{*}{ Season } & \multicolumn{4}{|c|}{ Observed T $\left({ }^{\circ} \mathrm{C}\right)$} & \multicolumn{4}{|c|}{ Modelled T $\left({ }^{\circ} \mathrm{C}\right)$} & \multirow[t]{2}{*}{ Corr. } \\
\hline & Mean & $\mathrm{SD}$ & Min. & Max. & Mean & SD & Min. & Max. & \\
\hline Year & -6.3 & 1.7 & -12.2 & -3.1 & -6.4 & 1.0 & -8.9 & -4.0 & 0.61 \\
\hline Winter (DJ F) & -14.0 & 3.6 & -23.2 & -7.6 & -14.1 & 2.4 & -19.1 & -9.1 & 0.62 \\
\hline Spring (MAM) & -10.8 & 2.4 & -19.3 & -6.7 & -10.8 & 1.7 & -15.2 & -7.5 & 0.58 \\
\hline Summer (J J A) & 4.3 & 0.7 & 2.5 & 6.1 & 4.2 & 0.5 & 3.2 & 5.4 & 0.54 \\
\hline Autumn (SON) & -4.8 & 2.0 & -11.3 & -1.3 & -4.9 & 1.5 & -8.7 & -1.8 & 0.66 \\
\hline
\end{tabular}

Table 3. Precipitation at Svalbard Airport. For the series of observed and modelled annual and seasonal precipitation sums from 1912 to 1993, the following values are given: mean, standard deviation, absolute minimum and absolute maximum. Corr.: correlation coefficient between observed and modelled precipitation series

\begin{tabular}{|c|c|c|c|c|c|c|c|c|c|}
\hline \multirow[t]{2}{*}{ Season } & \multicolumn{4}{|c|}{ Observed P (mm) } & \multicolumn{4}{|c|}{ Modelled P (mm) } & \multirow[t]{2}{*}{ Corr. } \\
\hline & Mean & SD & Min. & Max. & Mean & SD & Min. & Max. & \\
\hline Year & 180.7 & 49.8 & 86.4 & 317.0 & 178.7 & 33.5 & 93.5 & 286.6 & 0.54 \\
\hline Winter (DJ F) & 53.4 & 24.3 & 16.8 & 140.0 & 52.8 & 11.5 & 24.5 & 86.8 & 0.40 \\
\hline Spring (MAM) & 35.6 & 10.4 & 6.4 & 125.9 & 34.3 & 13.6 & 10.6 & 65.5 & 0.60 \\
\hline Summer (J J A) & 43.7 & 21.2 & 3.0 & 114.0 & 43.7 & 18.7 & 8.3 & 100.8 & 0.57 \\
\hline Autumn (SON) & 48.1 & 17.0 & 18.4 & 109.0 & 47.9 & 13.1 & 21.5 & 79.1 & 0.54 \\
\hline
\end{tabular}




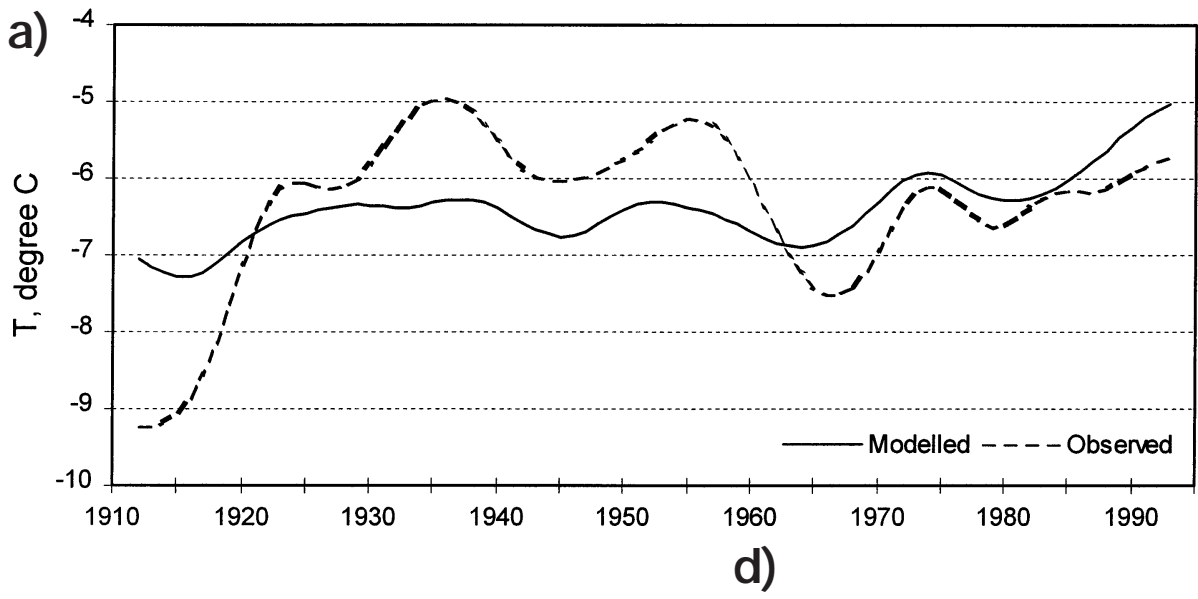

\section{b)}

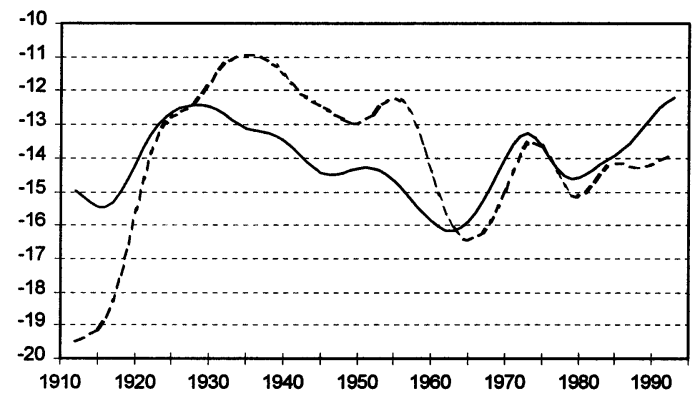

c)

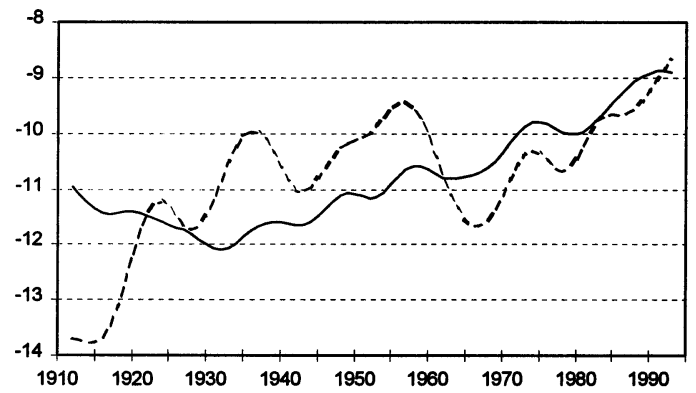

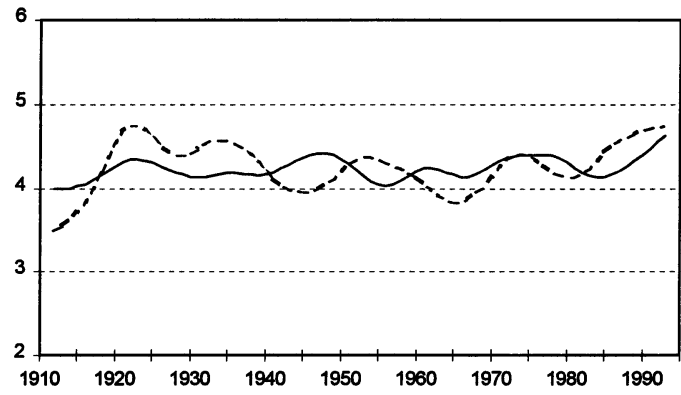

e)

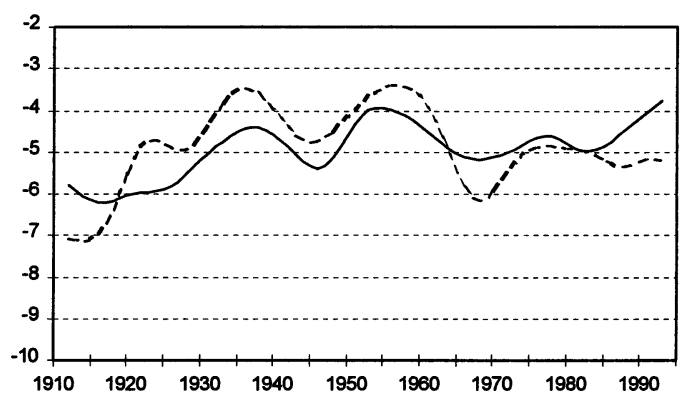

Fig. 4. Low-pass-filtered series of observed (dashed) and modelled (solid) temperature from Svalbard Airport. (a) Annual mean temperature, (b) winter (Dec-J an-Feb), (c) spring (M ar-A pr-M ay), (d) summer (J un-J ul-Aug), and (e) autumn (Sep-Oct-N ov)

mainly after 1950, while the increase in summer and autumn precipitation mainly took place earlier in the century. Annual precipitation increased by about 30\% during the period 1912 to 1996.

In order to investigate the degree to which the models reproduce decadal scale variability and long-term trends, a low-pass filter implying Gaussian weighting of the observed and modelled series was applied. The standard deviation of the Gaussian distribution was set to $3 \mathrm{yr}$. Figs. $4 \& 5$ show the filtered series of modelled versus observed temperature and precipitation. It is seen that the models reproduce some of the observed decadal scale variability and long-term trends, but not all features.
The warm periods in the 1930s and 1950s are not reproduced by the model, mainly because the modelled winter and spring temperatures were lower than observed. Neither is the cold period before 1920 reproduced. Consequently, the observed positive trend in annual mean temperatures before the 1930s and the negative trend from the 1930 s to the 1960 s are not satisfactorily accounted for. The observed positive trends in annual mean as well as winter and spring temperatures from the 1960s to present, on the other hand, are fairly well reproduced by the model.

Low-pass-filtered series of modelled versus observed precipitation (Fig. 5) indicate that the precipitation model actually is better skilled than the tempera- 


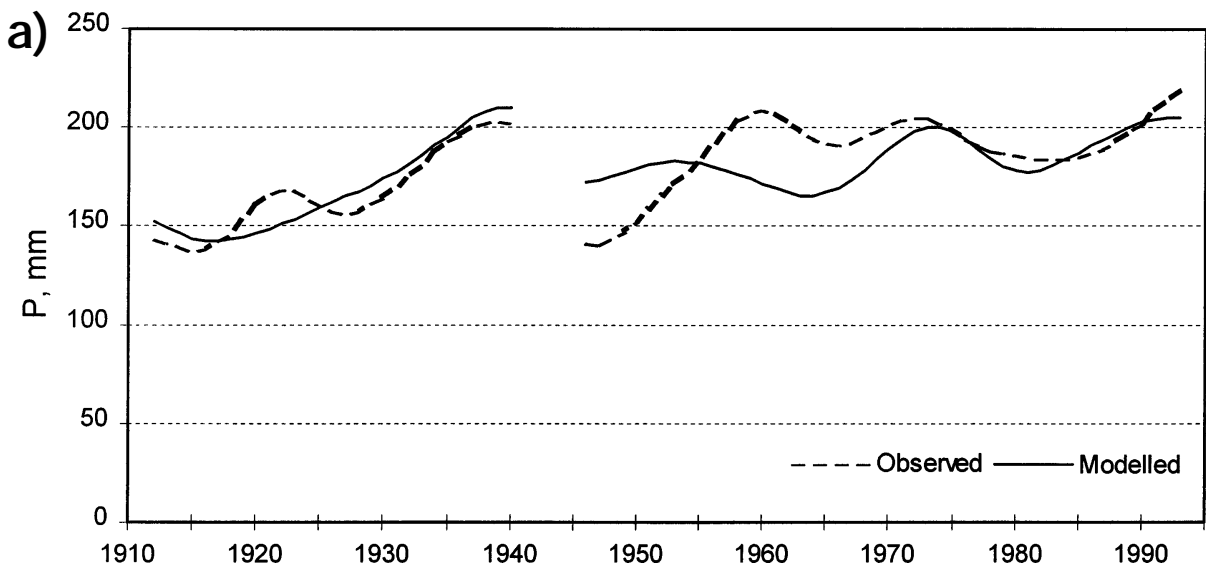

b)

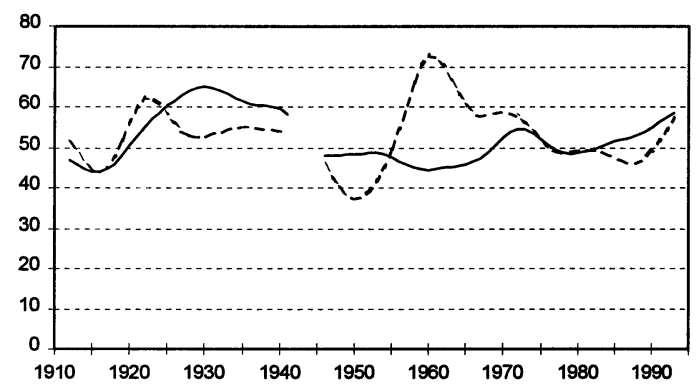

d)

c)

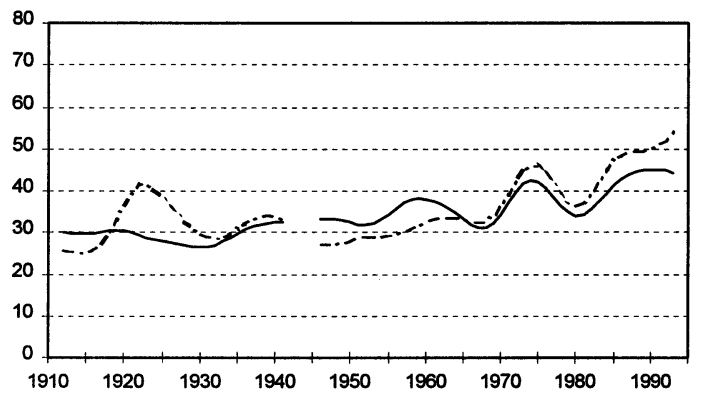

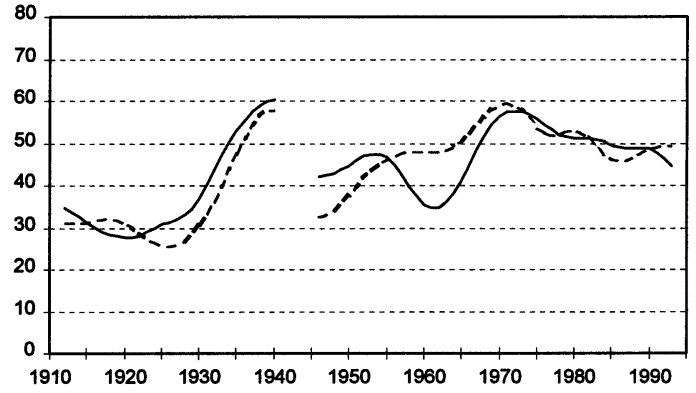

e)

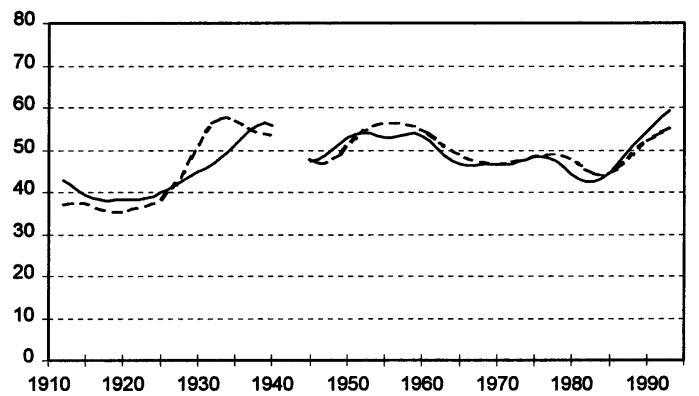

Fig. 5. Low-pass-filtered series of observed (dashed) and modelled (solid) precipitation from Svalbard Airport. (a) Annual precipitation sum, (b) winter (Dec-J an-Feb), (c) spring (M ar-A pr-M ay), (d) summer (J un-J ul-Aug), and (e) autumn (Sep-Oct-N ov)

ture models when it comes to decadal scale variability and long-term trends. The observed winter maximum around 1960 as well as the local winter and spring maxima in the early 1920s are probably due to measurement problems (see Section 5). Aside from these, the model accounts for most of the observed features in all seasons. It also accounts for the observed positive long-term trends in spring, summer, autumn and annual precipitation. Thus, even if the interannual and interseasonal variability in precipitation at Svalbard Airport is not very well modelled, the decadal scale and long-term variability is quite closely related to variations in the mean sea level pressure field.

\section{DISC USSION}

Hanssen-Bauer \& Førland (1998) show that it is mainly the pressure gradient terms of the models (Eq. 5) which account for the decadal scale and long-term variability in modelled temperature and precipitation. Thus, according to our model, variations in the average atmospheric advection can explain the positive trend in temperature observed at the Svalbard stations after 1960, but not the long-term temperature variations from 1912 to 1960. There are 3 possible reasons for this:

(1) The data prior to 1960 are of lower quality than in the later years. 
(2) The circulation conditions are insufficiently described by the simple model.

(3) The long-term temperature variation at Svalbard from 1912 to 1960 does not only reflect typical atmospheric circulation patterns.

\subsection{Data quality}

Concerning data quality, the long Svalbard Airport temperature series was composed of data from several stations (Nordli et al. 1996), and the adjustments to 'Svalbard Airport conditions', especially of the older data series, are more or less uncertain. There is, however, good agreement between the Svalbard Airport temperature series and other series from the Norwegian Arctic which started in the 1920s (Førland et al. 1997). It is thus concluded that the observed high temperatures of the 1930s and 1950s in the Norwegian Arctic are real. It has been difficult to confirm the very low temperatures at Svalbard Airport before 1920 by other measurements. However, some support is provided by Vinje (1997), who published a time series of the latitude of the average August ice edge (corresponding to maximum seasonal retreat) in the sector between $20^{\circ}$ and $45^{\circ} \mathrm{E}$ over the last $250 \mathrm{yr}$. The average August ice edge between 1910 and 1920 was further south than it was in any of the later decades, including the 1960s. It is therefore concluded that the modelled values are biased, while the observations from the period prior to 1920 probably are reasonably good.

Poor quality of the gridded air pressure data in the beginning of the series could also affect the modelled temperature values in this period. The gridded air pressure data in Arctic areas are based upon a rather coarse network of observations in the earlier years. However, if this is the reason for the poor performance of the temperature models, it is difficult to explain the ability of the precipitation model to reproduce the main observed decadal scale variations and long-term trends in precipitation during the whole series. The skill of the precipitation model thus supports the suggestion that the mismatch between observed and modelled temperatures does not primarily result from poor quality of the pressure series.

\subsection{Insufficient circulation model}

Description of the atmospheric circulation by using monthly averages of sea level pressure from 4 grid points implies a substantial simplification. Using pressure data from 9 grid points would allow the introduction of vorticity in the model. Using the mean sea level pressure field from a larger area would include even more information. Zorita \& von Storch (1999) describe several techniques for statistical downscaling, which may be used for modelling local precipitation and/or temperature from the mean sea level pressure field over a given area. It is highly probable that more advanced techniques would be more skilled than the present simple model, especially when it comes to modelling the interannual variability of seasonal precipitation and temperature. Still, it is questionable whether any of these techniques would be able to reproduce the observed low temperatures before 1920 and the high temperatures of the 1930s and the 1950s. Werner \& von Storch (1993) conclude that Canonical Correlation Analysis (CCA) fails to consistently link trends in long-term winter temperature from 1901 to 1980 at 11 Central European stations to changes in the North Atlantic/European SLP. Thus, even if substantially more of the year-to-year and season-to-season variance could be accounted for by using more advanced methods like CCA, this would probably not solve the problems connected with modelling of the long-term temperature trends.

\section{3. $\mathrm{C}$ hanges are not caused by circulation changes alone}

The remaining hypothesis is that the temperature models fail to produce the observed long-term variability in the earlier decades because these features were not primarily caused by variations in the average circulation conditions. In Section 5, it was mentioned that variations in the sea ice distribution and SST anomalies may be responsible for some of the unexplained variance. As the ocean and sea ice have longer 'memories' than the atmosphere, this could explain the similarity of the temperature residuals (observed minus modelled temperatures) for all seasons. Time series of the average August ice edge latitude valid for the sector between $20^{\circ}$ and $45^{\circ} \mathrm{E}$ (Vinje 1997) support the hypothesis that at least the low temperatures in the beginning of the series are caused by (for our century) unusually extensive sea ice in the area. This sea ice would effectively decouple the air masses from the underlying ocean. The ice edge series also shows that the August ice edge was rather far north during most of the 1930s and 1950s. In several of these years, the average August ice edge was at $80^{\circ} \mathrm{N}$ or more. This could indicate that unusually light sea ice conditions or, rather, the feedback from these conditions on the air temperature explains the shortcoming of the pure advection model during these decades. This explanation is supported by the fact that the high temperatures of the 1930s, relatively speaking, were more pro- 
nounced in the Norwegian Arctic than further south in the North Atlantic region (Hanssen-Bauer et al. 1996), and also greater than in the average curve for the Northern Hemisphere. Nevertheless, the average August ice edge in the 1980s was even further north than in the 1930s and the 1950s, so it is still unclear why the pure circulation model is able to reproduce the high temperatures of this decade. This could be investigated further by introducing additional predictors, e.g. the SST field and/or the average ice edge position, into the model for local temperature. Such additional predictors are obviously important if the intention is to use the model for statistical downscaling of temperature.

A nother potential cause of changes in the characteristics of air masses in the Svalbard region is changes in the aerosol forcing. The increased tropospheric aerosol concentration during the present century, especially after World War II (Kattenberg et al. 1996) may have influenced the radiation budget of the air masses, and thus affected cloudiness and other characteristics. This could be studied further by analysing long-term trends of cloudiness and maximum/minimum temperatures.

\section{MAIN CONCLUSIONS}

The observed long-term variation in precipitation on the west coast of Svalbard from 1912 to 1993 may be explained mainly by variation in the average atmospheric circulation conditions. Variations in circulation conditions can explain the statistically significant increase in the precipitation during spring, summer and autumn, as well as in annual precipitation. The mean annual precipitation increased by about 30\% during the period 1912 to 1996.

The temperature increase at Svalbard from the 1960s to the 1990s may to a large degree be explained by circulation. However, variations in circulation account for only a fraction of the observed temperature increase at Svalbard from 1912 to the 1930s and the temperature decrease from the 1930s to the 1960s.

The divergence between observed and modelled long-term temperatures from 1912 to 1960 emphasises the importance of applying long-term data series to investigate the covariation between atmospheric circulation and specific climate elements. By using only the last $30 \mathrm{yr}$ of the data series, the performance of the temperature model would apparently be satisfactory and the model would thus seem to be well suited for downscaling purposes.

The present study suggests that the mismatch between modelled and observed long-term temperature variation is caused neither by poor data quality nor an insufficient circulation model. The explanation is rather that additional predictors (SST, sea ice, cloudiness, etc.) are needed to model long-term temperature variations. This is in agreement with Werner \& von Storch (1993), who propose that the Central European temperature on time scales of several decades is controlled not only by circulation, but also by Atlantic SST.

On the other hand, the present analyses indicate that orographically influenced precipitation, more readily than temperature, may be simulated by using the mean sea level pressure field only. However, as increased temperature generally leads to increased amounts of precipitable water in the atmosphere, additional predictors should also be included in the precipitation model.

Our conclusions concerning the temperature increase after 1960 are in agreement with Hurrell (1995), who suggests that the recent temperature anomalies over the North Atlantic and the surrounding land masses are strongly related to the mean circulation patterns associated with the NAO. As noted by several authors (e.g. M orton 1998), this does not contradict the possibility of a 'greenhouse influence' on the temperature increase. The circulation conditions may very well be affected by the enhanced greenhouse effect.

Acknowledgement. We are indebted to 3 anonymous reviewers for constructive comments which were most helpful in improving the paper. This study was partly funded by the Norwegian Research Council (Contracts No. 112890/720 and 120656/720).

\section{LITERATURE CITED}

Førland E, Hanssen-Bauer I, N ordli Ø (1997) Climate statistics and long-term series of temperature and precipitation at Svalbard and Jan Mayen. DNMI Report 21/97 KLIMA, Norwegian M eteorological Institute, Oslo

Hanssen-Bauer I, Førland EJ (1998) Monthly precipitation and temperature at Svalbard modelled by mean sea level pressure. DNMI Report 9/98 KLIMA, Norwegian Meteorological Institute, Oslo

Hanssen-Bauer I, N ordli PØ, Førland EJ (1996) Principal component analyses of the NACD temperature series. DNMI Report 1/96 KLIMA, Norwegian Meteorological Institute, Oslo

Hisdal V, Finnekåsa $\varnothing$, Vinje T (1992) Radiation measurements in Ny-Ålesund, Spitsbergen 1981-1987. Medd N r 118, Norwegian Polar Institute, Oslo

Hurrell J W (1995) Decadal trends in the North Atlantic Oscillation: regional temperatures and precipitation. Science 269:676-679

Kattenberg A, Giorgi F, Grassl H, Meehl GA, Mitchell J FB, Stouffer RJ, Tokioka T, Weaver AJ, Wigley TML (1996) Climate models - projections on future climate. In: Houghton JT, Meira Filho LG, Callander BA, Harris N, Kattenberg A, M askell K (eds) Climate change 1995. University Press, Cambridge, p 285-357

Morton O (1998) The storm in the machine. New Scientist 157(2119):22-27 
Nordli PØ, Hanssen-Bauer I, Førland E (1996) Homogeneity analyses of temperature and precipitation series from Svalbard and Jan Mayen. DNMI Report 16/96 KLIMA, Norwegian M eteorological Institute, Oslo

Sneyers R (1990) On statistical analysis of series of observations. WMO Tech Note No. 143, WMO No. 415. WMO, Geneva

Tveito OE (1996) Trends and variability in North European pressure series. DNMI Report 27/96 KLIMA, Norwegian Meteorological Institute, Oslo

Vinje T (1982) Frequency distribution of sea ice in the Greenland and Barents Seas, 1971-80. Norwegian Polar Institute, Oslo

Vinje T (1997) On the variation during the past 400 years of

Editorial responsibility: Hans von Storch,

Geesthacht, Germany the Barents Sea ice edge position and northern hemisphere temperatures. Proceeding of the WCRP/ACSYS Conference on Polar Processes and Global Climate, Rosario Resort, Washington, USA, 3-6 N ov 1997. University of Washington, Washington, p 269-271

Vowinckel E, Orvig S (1970) The climate of the North Polar Basin. In: Orvig S (ed) Climates of the polar regions. Elsevier, Amsterdam

Zorita E, von Storch H (1999) A survey of statistical downscaling techniques. J Clim (in press)

Werner PC, von Storch H (1993) Interannual variability of Central European mean temperature in J anuary-February and its relation to large-scale circulation. Clim Res 3: 195-207

Submitted: A pril 27, 1998; Accepted: J uly 21, 1998

Proofs received from author(s): August 17, 1998 